\title{
Seasonal behaviour of the volatility on European stock markets
}

\author{
L. Jordán Sales ${ }^{1}$, R. $M^{\text {a }}$. Cáceres Apolinario ${ }^{1}$, O. Maroto Santana ${ }^{1}$ \\ $\&$ A. Rodríguez Caro ${ }^{2}$ \\ ${ }^{I}$ Department of Financial Economics and Accounting, \\ Las Palmas de Gran Canaria University, Spain \\ ${ }^{2}$ Departament of Quantitative Methods, \\ Las Palmas de Gran Canaria University, Spain
}

\begin{abstract}
The existence of seasonal behaviour in return and volatility of different international stock exchanges may be considered as an indication of nonintegrated financial markets. A type of this abnormal behaviour is the day of the week effect, which implies investment opportunities. This type of opportunity is studied in this paper, focused on the analysis of the day of the week effect on the major European stock markets using GARCH and T-ARCH models. Results show evidence in favour of day of the week effect in the volatility in the most of the studied countries.
\end{abstract}

Keywords: day of the week effect, volatility, GARCH, T-ARCH.

\section{Introduction}

The increasing internationalisation of the main economies from developed nations has given the investor additional choices when considering his portfolio. $\mathrm{He}$ is no longer obliged to focus his attention on the financial markets where the assets of his own country are listed in the stock market but instead may look towards other investment horizons whose markets offer opportunities to obtain greater results with respect to profit and risk. This scenery is characterised by significant relaxation of national barriers, thus allowing for the entrance of foreign capital, and its repercussions are seen in the considerable increase in international capital flows. 
Nevertheless, it is necessary to remember that investment opportunities in international markets depend on the degree of integration or segmentation that said markets possess. The presence of anomalies in international financial markets can be a clear sign that a lack of integration among these markets exists, thus investment opportunities derived from different behaviours in the generation of returns are available. Several studies have centred on relative anomalies in the seasonality of distinct financial markets of developed countries as an explanation to why there is an absence of integration between international financial markets.

The objective of this paper is to empirically contrast the day of the week effect in the major European stock markets from July 1997 to March 2004. We will study not only return but volatility as well. The day of the week effect under a volatility context has not received much attention in the literature. The motivation for this paper comes from the growing process of integration of the distinct world economies and European economies in particular, resulting in an increasing correlation and synchronization among financial markets from different countries.

The paper is divided into the following sections. Section 2 presents a description of the database as well as the methodology employed in the paper. The estimations from the GARCH and T-ARCH models and the results are presented in Section 3. The paper ends with a summary of the main conclusions.

\section{Data and methodology}

The present paper used series of daily returns from the corresponding stock indices of the following European markets: Germany, Austria, Belgium, Denmark, Spain, France, The Netherlands, Italy, Portugal, The United Kingdom, The Czech Republic, Sweden and Switzerland.

The sampling dates begin with July 2, 1997 and end on March 22, 2004. The returns for each market are expressed in local currency and have been calculated as first differences in natural logarithms.

The analysis of the day of the week effect was carried out in the following manner. First we used five observation per week in order to avoid possible bias from the loss of information due to bank holidays. A total of 1754 yields were collected for each of the analysed markets. The indices used for each country market in our sample are DAX (Germany), ATX (Austria), BEL-20 (Belgium), KFX (Denmark), IBEX-35 (Spain), CAC-40 (France), AEX (Holland), MIB-30 (Italy), PSI-20 (Portugal), FTSE-100 (U. Kingdom), PX-50 (Czech Rep.), Stockholm General (Sweden), Swiss Market (Switzerland).

One of the most common seasonality anomalies is the day of the week effect. This analysis is based on the hypothesis that the yields produced by each security are not independent of the day of the week. An initial approximation that could contrast the day of the week effect can be carried out with a regression model. They included five dummy variables, one for each day of the week.

$$
r_{i t}=\beta_{1} D_{1 t}+\beta_{2} D_{2 t}+\beta_{3} D_{3 t}+\beta_{4} D_{4 t}+\beta_{5} D_{5 t}+\varepsilon_{t}
$$


where:

rit : is the daily yield of the financial asset

Djt : are dummy variables which take on the value 1 if the corresponding return for day $\mathrm{t}$ is a Monday, Tuesday, Wednesday, Thursday or Friday, respectively and 0 otherwise.

$\beta j$ : are coefficients which represent the average return for each day of the week. $\varepsilon t:$ is the error term.

It is worth noting that even though the corresponding return on a specific day of the week is significantly different than zero, this does not imply seasonality. Thus it is necessary to perform a means test. This test verifies if the returns are independent of the day of the week that they are produced in, or on the contrary, they are characterised by statistically similar average returns. The rejection of the null hypothesis would imply that a day of the week effect is indeed present.

Nevertheless two serious problem arise with this approach. First, the residuals obtained from the regression model can be autocorrelated, thus creating errors in the inference. The second problem is that the variance of the residuals is not constant and possibly time-dependent.

A solution to the first type of problem was to introduce the returns with a oneweek delay into the regression model, as used in the works by Easton and Faff [6], Corredor and Santamaría [5] and Kyimaz and Berument [11], among others.

$$
r_{i t}=\beta_{1} D_{1 t}+\beta_{2} D_{2 t}+\beta_{3} D_{3 t}+\beta_{4} D_{4 t}+\beta_{5} D_{5 t}+\sum_{j=1}^{4} \beta_{j+5} \cdot r_{t-j}+\varepsilon_{t}
$$

ARCH models are proposed in order to correct the variability in the variance of the residuals. Engle [7] used this approach and it has the advantage that the conditional variance can be expressed as a function of past errors. These models assume that the variance of the residual term is not constant through time and is distributed as $\varepsilon_{t} \sim \operatorname{iid}\left(0, \sigma_{t}^{2}\right)$. The generalized version of these models was proposed by Bollerslev (1986) and is expressed by the sum of a moving-average polynomial of order q plus an autoregressive polynomial of order $\mathrm{p}$ :

Others works by Baillie and Bollerslev [2], Hsieh [9], Copeland and Wang [4] and Kyimaz and Berument [11] also include dummy variables which account for the possible stationary effects within the equation of variance. The result of this approach is that joint estimates of the day of the week effects are obtained, not only in the mean but also in the conditional variance.

$$
\begin{gathered}
r_{i t}=\beta_{1} D_{1 t}+\beta_{2} D_{2 t}+\beta_{3} D_{3 t}+\beta_{4} D_{4 t}+\beta_{5} D_{5 t}+\sum_{j=1}^{4} \beta_{j+5} r_{t-j}+\varepsilon_{t} \\
\varepsilon_{t} \sim i i d\left(0, \sigma_{t}^{2}\right) \\
\sigma_{t}^{2}=\alpha_{1} D_{1}+\alpha_{2} D_{2}+\alpha_{3} D_{3}+\alpha_{4} D_{4}+\alpha_{5} D_{5}+\sum_{i=1}^{q} \alpha_{5+i} \varepsilon_{t-i}^{2}+\sum_{i=1}^{p} \gamma_{i} \sigma_{t-i}^{2}
\end{gathered}
$$

This model is characterised by its symmetric behaviour since the volatility is invariant during gains and losses of the stock quotations. Nevertheless, it is well known that the impacts in the volatility in positive and negative yields need not 
have the same effect. Kiymaz and Berumet [11] have argued that on many occasions the obtained volatility from a negative return is usually greater than the corresponding one during a gain in the stock quotation that is being analysed. The asymmetric T-ARCH model is used in this case to confirm the existence or absence of any asymmetric behaviour, which is known as the leverage effect.

The T-ARCH model introduced by Zakoian [14] and Glosten et al. [8] contains a structure which is similar to the symmetric GARCH model with one exception. They include a term where the $\lambda$ parameter is used to indicate the existence of differentiated behaviour in the volatility against positive and negative shocks. The generalised structure of the T-ARCH model follows:

$$
\begin{gathered}
r_{i t}=\beta_{1} D_{1 t}+\beta_{2} D_{2 t}+\beta_{3} D_{3 t}+\beta_{4} D_{4 t}+\beta_{5} D_{5 t}+\sum_{j=1}^{4} \beta_{j+5} r_{t-j}+\varepsilon_{t} \\
\varepsilon_{t} \sim i i d\left(0, \sigma_{t}^{2}\right) \\
\sigma_{t}^{2}=\alpha_{1} D_{1}+\alpha_{2} D_{2}+\alpha_{3} D_{3}+\alpha_{4} D_{4}+\alpha_{5} D_{5}+\sum_{i=1}^{q} \alpha_{5+i} \varepsilon_{t-i}^{2}+\sum_{i=1}^{p} \gamma_{i} \sigma_{t-i}^{2}+\lambda \varepsilon_{t-1}^{2} d_{t-1}
\end{gathered}
$$

where dt-1 is a dicotomic variable which takes on value 1 when the stock quote falls in a period and 0 for increments of the stock quotation.

\section{Estimation of the models and empirical results}

The study of seasonality in the returns and volatility for the European stock markets that are included in our sample is carried out based on obtained estimates from the daily returns of each one of the stock markets considered.

\subsection{The study of day of the week effect on returns}

Four dummy variables have been used to account for seasonality in each of the stock exchanges for each workday except Wednesday. The regression model follows:

$$
r_{i t}=\alpha+\beta_{1} D_{1 t}+\beta_{2} D_{2 t}+\beta_{4} D_{4 t}+\beta_{5} D_{5 t}+\sum_{j=1}^{4} \beta_{j+5} \cdot r_{t-j}+\varepsilon_{t}
$$

The individual meaning for each one of the dicotomic variables could reveal the presence of an atypical yield during a day of the week with respect to that of Wednesday. Not only is the statistical significance of each dummy variable studied but also possible structure in the autoregressive portion and in the moving average which includes the regression model.

The obtained results are summarised in Table 1 and indicate that the day of the week effect is not evident in most European stock markets since the yield for each day of the week is not especially different than that of other days. This fact tells us that the return for the most important representative European markets is independent of the day of the week. Nonetheless, a stationary effect can be observed on Mondays for the representative indexes of France and Sweden since the yields on this day are greater than the rest of the week. This result does not coincide with those obtained in most empirical studies where average Monday 
returns are usually significantly less than the average returns for the other days of the week. A similar finding is observed in Sweden where Friday yields are much greater than those for the other days of the week, thus recalling the Friday effect for this specific market.

Table 1: $\quad$ Day of the week effect on returns.

\begin{tabular}{l|l|l|l}
\hline \multicolumn{1}{c|}{ Country } & \multicolumn{1}{|c|}{$\begin{array}{c}\text { Significant } \\
\text { variables }\end{array}$} & \multicolumn{1}{c}{ Country } & \multicolumn{1}{c}{$\begin{array}{c}\text { Significant } \\
\text { variables }\end{array}$} \\
\hline Germany & -- & Italy & MA(4) \\
Austria & MA(1), MA(3), MA(4) & Portugal & AR(1), AR(3) \\
Belgium & AR(1) & U. Kingdom & MA(3) \\
Denmark & AR(1) & Czech Rep. & AR(1) \\
Spain & -- & Sweden & D1, D5, AR(1) \\
France & D1 & Switzerland & AR(1) \\
Holland & -- & & \\
\hline
\end{tabular}

\subsection{Day of the week effect on volatility}

The importance of an analysis for the anomalies for distinct stock markets with respect to yields encountered for the day of the week cannot be ignored. The aim of each investor is to maximize the binomial yield-risk from his investment. Thus it is especially important to analyse fluctuations which are produced in the same markets. That is why both symmetric and asymmetric models have also been used to study their variance. We have included the earlier dummy variables to the equation of variance, similarly to Kyimaz and Berument [11] in order to collect possible stationary effects which may arise.

\subsubsection{GARCH model}

The structure for the equation of estimated variance follows:

$$
\sigma_{t}^{2}=\alpha_{0}+\alpha_{1} D_{1}+\alpha_{2} D_{2}+\alpha_{4} D_{4}+\alpha_{5} D_{5}+\sum_{i=1}^{q} \alpha_{5+i} \varepsilon_{t-i}^{2}+\sum_{i=1}^{p} \gamma_{i} \sigma_{t-i}^{2}
$$

Table 2 presents the results derived from the day of the week effect on volatility for each stock market index, as well as the GARCH structure for each series.

Table 2: $\quad$ Day of the week effect on variance: GARCH model.

\begin{tabular}{l|c|c|l|c|c}
\hline \multicolumn{1}{c|}{ Country } & $\begin{array}{c}\text { GARCH } \\
\text { structure }\end{array}$ & $\begin{array}{c}\text { Significant } \\
\text { variables }\end{array}$ & \multicolumn{1}{|c|}{ Country } & $\begin{array}{c}\text { GARCH } \\
\text { structure }\end{array}$ & $\begin{array}{c}\text { Significant } \\
\text { variables }\end{array}$ \\
\hline Germany & $(1,2)$ & D2, D5 & Italy & $(1,1)$ & D1, D4 \\
Austria & $(1,1)$ & D2, D5 & Portugal & $(1,1)$ & -- \\
Belgium & $(1,1)$ & D4, D5 & U. K & $(1,1)$ & D2 \\
Denmark & $(1,1)$ & D1, D5 & Czech Rep. & $(1,1)$ & -- \\
Spain & $(1,1)$ & D1, D4 & Sweden & $(1,1)$ & D2, D5 \\
France & $(1,1)$ & D4 & Switzerland & $(1,1)$ & D1, D4 \\
Holland & $(1,1)$ & D1, D4 & & & \\
\hline
\end{tabular}


The table shows that the resultant structure for all markets except Germany is GARCH $(1,1)$. This structure is the most appropriate for studying financial time series according to Lamoreux and Lastrapes (1990). The case of Germany is characterised by a GARCH $(1,2)$ structure.

With regards to volatility during each day of the week, we did not find common behaviour in the day of the week effect in the equation of conditional variance. This finding is in agreement with Kyimaz and Berument [11]. There is, however, presence of abnormal volatility on Mondays and Fridays in Denmark. Other observations include significantly distinct volatility on Mondays and Thursdays, with respect to Wednesday, in Spain, Holland, Italy and Switzerland. The case is different for abnormal volatilities for the United Kingdom and France, where the days are Tuesdays and Thursdays, respectively. Seasonal behaviour is also apparent on Tuesdays and Fridays for the cases of Germany, Austria and Sweden. Abnormal volatility occurs on Thursdays and Fridays in Belgium. Finally, Portugal and the Czech Republic show no changes with regards to the day of the week.

A general statement can be made for all of the markets that exhibit seasonal behaviour in the volatility. Mondays and Thursday are always greater than Wednesdays, while the opposite is true for Tuesdays and Fridays, that is, the yields are lesser than those experienced on Wednesday, except Friday in the Belgian market. The results derived from the ARCH-LM test and the Q statistic of the standardised residuals reveal that an $\mathrm{ARCH}$ effect is not present in the corresponding residuals of the estimates for these financial markets. Thus, there is no problem of specification in these models.

Consequently the day of the week effect in volatility in distinct European financial markets is present even though no common behaviour is noted among the respective countries.

\subsubsection{T-ARCH model}

As pointed out earlier, volatility can differ significantly, depending upon the sign of the obtained yield for each period. For this reason we estimate volatility using a T-ARCH model which incorporates possible asymmetric behaviour. The structure for the equation of variance follows:

$$
\sigma_{t}^{2}=\alpha_{1} D_{1}+\alpha_{2} D_{2}+\alpha_{3} D_{3}+\alpha_{4} D_{4}+\alpha_{5} D_{5}+\sum_{i=1}^{q} \alpha_{5+i} \varepsilon_{t-i}^{2}+\sum_{i=1}^{p} \gamma_{i} \sigma_{t-i}^{2}+\lambda \varepsilon_{t-1}^{2} d_{t-1}
$$

Table 3 presents the obtained results from the analysis of the volatility in the day of the week for each stock market index in addition to the T-ARCH structure for each series.

The inclusion of a parameter which accounts for asymmetric behaviour produces clear results in this table. The most common structure in all of the markets is a GARCH $(1,1)$, whereas Spain, France, Holland and Sweden follow a GARCH $(0,1)$. Finally it should be noted that Germany resembles a GARCH $(2,1)$ structure.

The asymmetric behaviour in all markets except the Czech Republic needs to be pointed out. Thus the gains and losses in each one of the stock markets in our 
sample affect in volatility in a different way. The use of an additional parameter in the T-ARCH model for asymmetric behaviour leads to different results than those from the symmetric GARCH model, with the expected exception in the Czech Republic, whose results were the same for both models. The day of the week effect reveals a similar behaviour pattern in the equation of variance as in the earlier model, that is, greater volatility on Mondays and Thursdays with respect to Wednesdays, and lesser volatility on Tuesdays and Fridays, except on Mondays in the United Kingdom.

Table 3: $\quad$ Day of the week effect on variance: T-ARCH model.

\begin{tabular}{lcclcc}
\hline Country & $\begin{array}{c}\text { GARCH } \\
\text { structure }\end{array}$ & $\begin{array}{c}\text { Significant } \\
\text { Variables }\end{array}$ & \multicolumn{1}{c}{ Country } & $\begin{array}{c}\text { GARCH } \\
\text { structure }\end{array}$ & $\begin{array}{c}\text { Significant } \\
\text { variables }\end{array}$ \\
\hline Germany & $(2,1)$ & D2 & Italy & $(1,1)$ & D1, D4 \\
Austria & $(1,1)$ & D2, D5 & Portugal & $(1,1)$ & D1 \\
Belgium & $(1,1)$ & D2 & U.Kingdom & $(1,1)$ & D1 \\
Denmark & $(1,1)$ & D1, D5 & Czech Rep. & $(1,1)$ & -- \\
Spain & $(0,1)$ & D1, D4 & Sweden & $(0,1)$ & D1, D2, D4, D5 \\
France & $(0,1)$ & -- & Switzerland & $(1,1)$ & D1, D4 \\
Holland & $(0,1)$ & D1, D4 & & & \\
\hline
\end{tabular}

The results from the ARCH-LM test and the Q statistic from the standardized residuals indicate that no effect is present in the corresponding remainders of the estimates of the financial markets. Thus, we do not encounter specification problems in this model.

The following observations can be made regarding the day of the week effect based on the estimation of variance with an asymmetric model. First, a Monday effect takes place in Portugal and the United Kingdom, while a Tuesday effect occurs in Germany and Belgium. Secondly, all other countries except Sweden present seasonal behaviour in two days of the week. Thirdly, this behaviour is seen on Mondays and Thursday in Spain, Holland, Italy and Switzerland. On the other hand, Tuesdays and Fridays are statistically significant in Austria, as opposed to Mondays and Fridays in Denmark. Finally, the Swedish market demonstrates volatility each day of the week with respect to Wednesday.

\section{Conclusions}

Investors that are interested in including international markets in their portfolio need to know if these markets are integrated or not. We pursued the answer to this question by studying possible seasonality in international markets. Our analysis focused on an empirical comparison of the day of the week effect in the major European markets from July 1977 to March 2004, and included not only returns but volatility as well.

To begin with, we should note that most European markets do not reflect a day of the week effect since the results for each day do not differ significantly from the other days of the week. The returns in these markets are based on 
representative indexes and reveal independence concerning which day of the week the return is calculated on. Nevertheless a seasonal effect can be observed on Mondays for the French and Swedish markets. The Swedish markets also reflects a significantly higher return on Fridays as opposed to the remaining days of the week.

With respect to the existence of abnormal volatility in the equation of conditional variance in the European markets, the following can be observed. A day of the week effect is present in all of the financial markets except in Portugal and the Czech Republic, where a symmetric model is applied. Exceptions are found in France and the Czech Republic, using an asymmetric T-ARCH model. Nevertheless, this effect does not agree with other analysed financial markets. However if we introduce a parameter which accounts for different behaviour in the volatility of the stock market indexes, then continuity in the day of the week effect becomes evident, differentiating the rise and fall of prices. Its presence is unlike that of the GARCH model because the statistical significance of the day of the week in the symmetric model in some cases could have been affected by asymmetric effects that were considered in the structure of the variance in the model.

Seasonality in conditional volatility in specific markets follow a similar behaviour pattern independent of the type of model that is being used. Mondays and Thursdays are more uncertain than on Wednesdays, while the Wednesday measure is lower than that of Tuesdays and Fridays.

Even though initially there does not seem to be a day of the week effect in yields from different European markets, an analysis of the conditional variance verifies that the extreme shifts observed in the major stock markets of each country indicate the absence of complete integration among all markets. This finding can be useful for an investor who is looking for investment instrument opportunities based on the change in volatility of these financial markets during specific days of the week.

\section{References}

[1] Aggarwal R. \& P. Rivoli (1989): "Seasonal and day of the week effect in four emerging stock markets", Financial Review, 24, pp. 541-550.

[2] Baillie, R. T. \& T. Bollerslev (1989): "The Message in Daily Exchange Rates: A Conditional-Variance Tale", Journal of Business and Economic Statistics, 7, 3, pp. 297-305.

[3] Climent, F. \& V. Meneu (1999): "La Globalización de los mercados internacionales", Actualidad Financiera, noviembre, pp. 3-15.

[4] Copeland, L. \& P. Wang (1994): "Estimating Daily Seasonality in Foreign Exchange Rate Changes", Journal of Forecasting, 13 , pp. 519-528.

[5] Corredor, P. \& R. Santamaría (1996): "El efecto día de la semana: resultados sobre algunos mercados de valores europeos", Revista española de Financiación y Contabilidad, XXV, 86, pp. 235-252. 
[6] Easton, S. \& R. Faff (1994): “An Examination of the Robustness of the Day of the week Effect in Australia", Applied Financial Economics, 4, pp. 99-110.

[7] Engle, R.F. (1982): “Autoregressive Conditional Heteroskedasticity with Estimates of the Variance of United Kingdom Inflation", Econometrica, 50, pp. 987-1007.

[8] Glosten, L. R., R. Jagannathan \& D. E. Runkle (1993): “On the relation between the expected value and the volatility of the nominal excess return on stocks", Journal of Finance, 48, pp. 1779-1801.

[9] Hsieh, D. A. (1988): "The statistical properties of daily foreign exchange rates: 1974-1983”, Journal of International Economics, 24, pp. 129-145.

[10] Jacquillat, B. \& B. Solnik (1978): "Multinational are Poor Tools for Diversification", Journal of Portfolio Management, 4, 2, Winter.

[11] Kyimaz, H. \& H. Berument (2001): "The day of the week effect on Stock Market Volatility", Journal of Economics and Finance, 25, 2, pp. 181-193.

[12] Lamoreux C. \& W. Lastrapes (1990): "Persistence in variance, structural change, and the GARCH model", Journal of Business and Economic Statistics, 2, pp. 225-234.

[13] Torrero, A. (1999): "La Importancia de las Bolsas en la internacionalización de las finanzas", Análisis Financiero, 79, pp. 62-77.

[14] Zakoian, J. M. (1990): Threshold Heteroskedasticity Models, manuscript, CREST, INSEE. 